\title{
Magnesium but not nicotinamide prevents vascular calcification in experimental uraemia
}

Citation for published version (APA):

Kaesler, N., Goettsch, C., Weis, D., Schurgers, L., Hellmann, B., Floege, J., \& Kramann, R. (2020).

Magnesium but not nicotinamide prevents vascular calcification in experimental uraemia. Nephrology Dialysis Transplantation, 35(1), 65-73. https://doi.org/10.1093/ndt/gfy410

Document status and date:

Published: 01/01/2020

DOI:

10.1093/ndt/gfy410

Document Version:

Publisher's PDF, also known as Version of record

Document license:

Taverne

Please check the document version of this publication:

- A submitted manuscript is the version of the article upon submission and before peer-review. There can be important differences between the submitted version and the official published version of record.

People interested in the research are advised to contact the author for the final version of the publication, or visit the DOI to the publisher's website.

- The final author version and the galley proof are versions of the publication after peer review.

- The final published version features the final layout of the paper including the volume, issue and page numbers.

Link to publication

\footnotetext{
General rights rights.

- You may freely distribute the URL identifying the publication in the public portal. please follow below link for the End User Agreement:

www.umlib.nl/taverne-license

Take down policy

If you believe that this document breaches copyright please contact us at:

repository@maastrichtuniversity.nl

providing details and we will investigate your claim.
}

Copyright and moral rights for the publications made accessible in the public portal are retained by the authors and/or other copyright owners and it is a condition of accessing publications that users recognise and abide by the legal requirements associated with these

- Users may download and print one copy of any publication from the public portal for the purpose of private study or research.

- You may not further distribute the material or use it for any profit-making activity or commercial gain

If the publication is distributed under the terms of Article $25 \mathrm{fa}$ of the Dutch Copyright Act, indicated by the "Taverne" license above, 


\title{
Magnesium but not nicotinamide prevents vascular calcification in experimental uraemia
}

\author{
Nadine Kaesler ${ }^{1}$, Claudia Goettsch ${ }^{2}$, Daniel Weis ${ }^{1}$, Leon Schurgers ${ }^{1,3}$, Burkhard Hellmann ${ }^{4}$, \\ Jürgen Floege ${ }^{1}$ and Rafael Kramann ${ }^{1,5}$ \\ ${ }^{1}$ Department of Nephrology, University Hospital of the RWTH Aachen, Aachen, Germany, ${ }^{2}$ Department of Cardiology, University Hospital of \\ the RWTH Aachen, Aachen, Germany, ${ }^{3}$ Department of Biochemistry, Cardiovascular Research Institute Maastricht, Maastricht, \\ The Netherlands, ${ }^{4}$ Medical Department, Medice Pharma, Iserlohn, Germany and ${ }^{5}$ Division of Nephrology and Transplantation, Department of \\ Internal Medicine, Erasmus Medical Center, Rotterdam, The Netherlands
}

Correspondence and offprint requests to: Rafael Kramann; E-mail: rkramann@gmx.net

\section{ABSTRACT}

Background. Optimal phosphate control is an unmet need in chronic kidney disease (CKD). High serum phosphate increases calcification burden and is associated with mortality and cardiovascular disease in CKD. Nicotinamide (NA) alone or in combination with calcium-free phosphate binders might be a strategy to reduce phosphate levels and calcification and thus impact cardiovascular disease in CKD.

Methods. We studied the effect of NA alone and in combination with magnesium carbonate $\left(\mathrm{MgCO}_{3}\right)$ as a potential novel treatment strategy. CKD was induced in dilute brown nonagouti/2 mice by subtotal nephrectomy followed by a highphosphate diet (HP) and 7 weeks of treatment with NA, $\mathrm{MgCO}_{3}$ or their combination. Control mice underwent subtotal nephrectomy and received an HP or underwent sham surgery and received standard chow plus NA.

Results. CKD mice showed increased serum fibroblast growth factor 23 and calcium-phosphate product that was normalized by all treatment regimes. NA alone increased soft tissue and vascular calcification, whereas any treatment with $\mathrm{MgCO}_{3}$ significantly reduced calcification severity in CKD. While $\mathrm{MgCO}_{3}$ supplementation alone resulted in decreased calcification severity, it resulted in increased intestinal expression of the phosphate transporters type II sodium-dependent phosphate transporter 1 (Pit-1). Combined therapy of $\mathrm{MgCO}_{3}$ and NA reduced tissue calcification and normalized expression levels of intestinal phosphate transporter proteins.

Conclusions. In conclusion, the data indicate that NA increases while $\mathrm{MgCO}_{3}$ reduces ectopic calcification severity. Augmented expression of intestinal phosphate transporters by $\mathrm{MgCO}_{3}$ treatment was abolished by the addition of NA. However, the clinical relevance of the latter remains to be explored. Importantly, the data suggest no benefit of NA regarding treatment of calcification in addition to $\mathrm{MgCO}_{3}$.
Keywords: chronic kidney disease, hyperphosphataemia, nicotinamide, phosphate binders, vascular calcification

\section{INTRODUCTION}

The number of patients with chronic kidney disease (CKD) and end-stage renal disease (ESRD) is increasing and the global prevalence has reached $>10 \%$ [1]. Cardiovascular morbidity and mortality are dramatically high in CKD and ESRD [2-4]. Arterial calcification, in media and intima, contributes centrally to this excess mortality, as it predicts cardiovascular events; it affects plaque stability and also stiffens the aorta by increasing afterload and contributing to chronic heart failure [5].

Disturbances of mineral and bone metabolism occur early in the course of CKD. When the glomerular filtration rate (GFR) declines, the kidney is unable to maintain phosphate balance due to reduced urinary phosphate excretion and the development of CKD mineral and bone disorder (CKD-MBD). Changes in CKD-MBD involve serum calcium and phosphate levels and endocrine axes controlling mineral and bone metabolism. The latter include soluble Klotho, fibroblast growth factor 23 (FGF23), vitamin D and parathyroid hormone as well as altered concentrations or activity of local inhibitors of calcification such as fetuin A and matrix gla protein.

Hyperphosphataemia is an independent predictor of cardiovascular disease, cardiovascular calcifications and mortality in CKD and even mild elevations in serum phosphate may increase the risk of vascular and valvular calcification [6-8]. Phosphate restriction significantly reduced mortality in uraemic rats with established vascular calcification [9]. Patients with CKD and ESRD are commonly prescribed phosphate binders to control hyperphosphataemia and thus slow down or stop the progression of vascular and soft tissue calcification [10]. However, phosphate binder therapy results in a high pill burden, and there is an ongoing discussion on the importance of 
the type of phosphate binders for progression of calcification and improved survival in $\mathrm{CKD}$, that is, calcium-free versus calcium-containing $[11,12]$. Importantly, despite various phosphate binders on the market, the reduction of serum phosphate often remains insufficient and many CKD patients still have hyperphosphataemia [13]. Some phosphate binders contain magnesium (magnesium carbonate, magnesium hydroxide). Magnesium-containing binders were shown to reduce vascular calcification in rats $[14,15]$. Also, magnesium has been reported to show pleiotropic beneficial effects, for example, on cardiac function and calcification. Hypomagnesaemia is associated with atrial fibrillation and hypertension [16]. Hypomagnesaemia is common in CKD, often triggered by proteinuria-induced tubular damages [17].

Phosphate absorption in the intestine occurs via passive paracellular and active sodium-dependent transporters [18]. The relative contribution of active phosphate absorption varies between 30 and $80 \%$, while the passive transport heavily depends on the intestinal phosphate concentration [19]. The type II sodium-dependent phosphate transporter ( $\mathrm{NaPi}-\mathrm{IIb})$ is the major contributor to active phosphate transport in the intestine [20]. A low-phosphate diet leads to an increase in the abundance of the intestinal NaPi-IIb transporters [21]. Similarly, oral phosphate binder therapy might result in up-regulation of intestinal phosphate transporters and thus increased phosphate absorption might counteract the treatment goal. Nicotinamide (NA) and nicotinic acid (both forms of niacin) are two available drugs that inhibit NaPi-IIb. Several small clinical studies have demonstrated that NA or niacin treatment reduces hyperphosphataemia and pill burden in dialysis patients [22, 23]. The results of two recent studies $[24,25]$ do not support stand-alone NaPi-IIb inhibition with either nicotinic acid or NA to control serum phosphate in CKD. Here we investigate the influence of NA compared with the phosphate binder magnesium carbonate $\left(\mathrm{MgCO}_{3}\right)$ and a combination of both using a mouse model of $\mathrm{CKD}$ with vascular and soft tissue calcification and in vitro assays of vascular smooth muscle cells (VSMCs) and Gli1 ${ }^{+}$progenitor calcification.

\section{MATERIALS AND METHODS}

\section{Mice}

The animal study was approved by the government authorities (Landesamt für Natur, Umwelt und Verbraucherschutz Nordrhein-Westfalen). For dose finding, healthy dilute brown non-agouti/2 (DBA/2) mice received NA via drinking water at three different dosages $(150,300$ or $600 \mu \mathrm{g} / \mathrm{mL})$. After 1 week we analysed inorganic serum phosphate and intestinal $\mathrm{NaPi}-\mathrm{IIb}$ expression. For the main study, female DBA/2 mice underwent 5/6 nephrectomy, 10 per group, as described previously [26]. After 1 week of recovery, a pelleted high-phosphate diet (HP) (1.65\% phosphate, $0.95 \%$ calcium; Ssniff, Soest, Germany) was initiated for 7 weeks. The diet was either supplemented with 3\% $\mathrm{MgCO}_{3}$ (Sigma-Aldrich, St Louis, MO, USA; \#M7179), $600 \mu \mathrm{g} / \mathrm{mL}$ NA (Medice, Iserlohn, Germany) (via drinking water) or in combination with each other. Control animals underwent a sham surgery. Blood pressure was measured non-invasively by tail vein occlusion on a CODA monitor (Kent Scientific, Torrington, CT, USA). After 7 weeks, animals were sacrificed.

\section{Biochemistry}

Serum urea, creatinine, calcium and phosphate were measured by clinical laboratory routine (Vitros 250, Ortho Clinical Diagnostics, Institut für Versuchstierkunde, Aachen, Germany). FGF23 was analysed by enzyme-linked immunosorbent assay (TECOmedical, Sissach, Switzerland; \#60-6300).

Tissue calcium was analysed by colorimetric o-cresolphthalein assay (Randox Laboratories, Crumlin, Northern Ireland). Therefore, total tissue calcium was mobilized by $10 \%$ formic acid overnight. Absorption was recorded on a Sunrise microplate absorbance reader (Tecan, Männedorf, Switzerland) at $550 \mathrm{~nm}$.

Myocardial magnesium was quantified using the BioCat Kit (BioCat GmbH, Heidelberg, Germany; K385-100-BV) according to the manufacturer's instructions.

Total protein was analysed by the bicinchoninic acid protein assay kit (Thermo Fisher, Waltham, MA, USA), and absorption was recorded on the Sunrise microplate absorbance reader (Tecan).

The fractional excretion of phosphate was calculated by the formula $\left(\right.$ phosphate $_{\text {urine }} \times$ creatinine $\left._{\text {blood }} \times 100\right) /$ phosphateblood $\times$ creatinine $_{\text {urine. }}$

Alkaline phosphatase activity was measured by the Biovision colorimetric kit (Biovision, Milpitas, CA, USA K412-500).

\section{Reverse transcription polymerase chain reaction (RT-PCR)}

Ribonucleic acid (RNA) was harvested from RNAlater (Qiagen, Venlo, The Netherlands; \#76104) stabilized tissue by the RNeasy mini kit (Qiagen; \#74104). The RNA concentration was measured on an Agilent RNA 6000 (Agilent Technologies, Santa Clara, CA, USA). RT was performed on a thermocycler in four steps. The quantitative polymerase chain reaction (qPCR) core kit was applied on a real-time PCR TaqMan System and glyceraldehyde 3-phosphate dehydrogenase (GAPDH) was used as a housekeeping gene. Primers were NaPi-IIb (SLC34A1; Biomol, Hamburg, Germany; \#VMPS-6022), Pit-1 (SLC20A1; Biomol; \#VMPS-5953), NaPi-IIb (sense: CCTGGGACCTGC CTGAACT, anti-sense: AATGCAGAGCGTCTTCCCTTT) and GAPDH (sense: AGATGGTGATGGGCTTCCC, antisense: GGCAAATTCAACGGCACAGT).

\section{Von Kossa staining}

The localization of calcium deposits was visualized by von Kossa staining. Briefly, sections were immersed in $1 \%$ aqueous silver nitrate solution for $5 \mathrm{~min}$. After washing, samples were incubated in a solution of 5\% sodium carbonate and $9.25 \%$ formalin for $1 \mathrm{~min}$. After a second rinse, sections were developed using sodium thiosulphate (5\%) for $5 \mathrm{~min}$ and counterstained in $0.1 \%$ safranin-O, followed by a final rinse with tap water.

\section{Immunofluorescence}

The small intestine was fixed in $4 \%$ paraformaldehyde, embedded in paraffin and cut on a rotary microtome. After deparaffination, slices were stained for NaPi-IIa (SLC34-A1; Biorbyt, 
Cambridge, UK; \#orb195991), NaPi-IIb (SLC34-A2; Abcam, Cambridge, UK; \#Ab122431) and Pit-1 (SLC20-A1; Thermo Fisher; \#PA5-28182). A fluorescent secondary antibody was used to visualize positive staining. Pictures were taken on a Biorevo microscope (Keyence, Osaka, Japan; BZ-9000E) and analysed planimetrically by manual counting of the fluorescence-positive area.

\section{Cell culture}

Human VSMCs were cultured in SMC growth medium 2 (SMC-GM2; PromoCell, Heidelberg, Germany) supplemented with epidermal growth factor $(0.5 \mathrm{ng} / \mathrm{mL})$, insulin $(5 \mu \mathrm{g} / \mathrm{mL})$, basic fibroblast growth factor-B $(2 \mathrm{ng} / \mathrm{mL})$ and foetal bovine serum (FBS) (5\%). They were cultured for up to 21 days in the presence of either control medium (Dulbecco's modified Eagle's medium, 10\% FBS, 1\% penicillin/streptomycin) or osteogenic medium (consisting of control medium supplemented with $10 \mathrm{nM}$ dexamethasone, $10 \mathrm{mM} \beta$-glycerol phosphate and $100 \mu \mathrm{M}$ l-ascorbate phosphate).

$\mathrm{Gli1}^{+}$cells were isolated from bone chips of transgenic Gli1CreER; tdTomato mice as described previously [27] and cultivated in alpha-MEM, 10\% foetal calf serum. For osteogenic differentiation, StemXVivo medium (R\&D Systems, Minneapolis, MN, USA) was used according to the manufacturer's instructions for 14 days.

Both cell types were treated with either NA (Medice; $10 \mu \mathrm{M}$, added directly to the cell culture medium), magnesium (AppliChem, Darmstadt, Germany; magnesium carbonate, $1 \mu \mathrm{M}$, added directly to the cell culture medium), magnesium and NA in combination or N-methyl-2-pyridone-5-carboxamide (2PY) (LGCStandards, Middlesex, UK; $N$-methyl-2-pyridone-5-carboxamide $0.1 \mu \mathrm{M}, 10 \mu \mathrm{M}$, added directly to the cell culture medium) or $N$-methyl-4-pyridone-3-carboxamide (4PY) [Biozol, Eching, Germany; 1,4-Dihydro-1-methyl-4-oxo-3-pyridine carboxamide $0.1 \mu \mathrm{M}, 10 \mu \mathrm{M}$, dissolved at $10 \mathrm{mM}$ in dimethyl sulfoxide (DMSO) versus DMSO control] in addition to osteogenic medium. Medium was exchanged every other day.

\section{Statistics}

We used one-way analysis of variance for comparisons between groups, followed by Tukey's multiple comparison test. Equal variances were tested with Bartlett's method. The D'Agostino and Pearson normality test was performed to check for Gaussian distribution. Significance was defined as $\mathrm{P}>0.05$.

\section{Echocardiography}

Transthoracic echocardiography was performed on a Vevo 770 (Visualsonics, Toronto, ON, Canada) as described earlier [28]. Briefly, mice were anaesthetized with isoflurane (Abbott, Lake Bluff, IL, USA) and placed on a warming plate at $37^{\circ} \mathrm{C}$. Breathing and heart rate were monitored continuously. Left ventricular (LV) mass was calculated in the Mmode in the long axis view from the Devereux formula. Ejection fraction (EF) as an index for global LV systolic function was measured by the Simpson method. Stroke volume was estimated as the difference between the LV end-systolic and end-diastolic volumes. Pulse-wave velocity in the right common carotid artery and the abdominal aorta was measured using the transit-time method in a two-dimensional mode. In the carotid artery, the proximal pulse-wave signal was obtained $1 \mathrm{~mm}$ behind the origin of the subclavian artery, the distal signal $1 \mathrm{~mm}$ before the carotid bifurcation. The transit time was found by subtracting the distal arrival time between the electrocardiogram R-wave peak and the foot of velocity upstroke from the similarly determined proximal arrival time $[\mathrm{PWV}=\Delta \mathrm{d} /($ Ptdist - Ptprox $)]$, where $\mathrm{Pt}$ is the time point of the proximal or distal pulse-wave signal and $\Delta \mathrm{d}$ is the distance between the two measurements.

\section{RESULTS}

\section{Dose-finding experiment of NA in mice}

We first sought to establish an optimal dose of NA that would significantly reduce serum phosphate levels in mice exposed to HP. Therefore DBA/2 wild-type mice received HP ( $1.65 \%$ phosphorus, $0.95 \%$ calcium) with either no treatment or three different concentrations of NA in drinking water $(n=7$ mice/group, all females; Figure 1A). Mice were sacrificed at 1 week after initiation of the HP diet and NA treatment. The total NA dosage per mouse was calculated based on the average drinking amount $(\mathrm{mL} / \mathrm{mouse} / 24 \mathrm{~h})$ resulting in an average daily intake of $43 \mathrm{mg} \mathrm{NA} / \mathrm{kg}$ bodyweight (low dose) versus $70 \mathrm{mg} / \mathrm{kg}$ (medium dose) and $124 \mathrm{mg} / \mathrm{kg}$ (high dose). Only the high-dose NA resulted in a significant decrease in serum phosphate (Figure 1B). High-dose NA treatment also showed a tendency towards a reduced calcium-phosphate product, however, this did not reach significance (Figure 1C). Of note, we did not observe any significant changes of alkaline phosphatase activity and $\mathrm{NaPi}$-IIb expression in the ileum in this dose-finding experiment (Supplementary data, Figure S1).

\section{$\mathrm{NA}$ and magnesium in CKD-associated cardiovascular calcification}

We next sought to determine the effect of NA treatment either alone or in combination with $\mathrm{MgCO}_{3}$ in a mouse model of $\mathrm{CKD}$ with vascular and soft tissue calcification. For this, female DBA/2 mice (10 per group) underwent subtotal nephrectomy followed by $\mathrm{HP}$ followed by no treatment (CKD control) or the addition of either $3 \% \mathrm{MgCO}_{3}\left(\mathrm{CKD}+\mathrm{MgCO}_{3}\right)$ or $600 \mu \mathrm{g} / \mathrm{mL}$ $\mathrm{NA}(\mathrm{CKD}+\mathrm{NA})$ or a combination of both $\left(\mathrm{CKD}+\mathrm{MgCO}_{3} / \mathrm{NA}\right.$; Figure 2A). Mortality in all CKD groups was $10 \%$. Sham surgery followed by standard chow plus NA treatment served as the control group (sham). As expected, the CKD control mice had a decreased GFR (Figure 2B). In the CKD mice receiving $\mathrm{MgCO}_{3}$, the GFR significantly improved. While none of the treatments resulted in significant reductions in the increased serum phosphate level in CKD (Figure 2G), the increased calcium-phosphate product was significantly elevated only in the CKD control group (Figure 2C). Serum calcium levels were not significantly different between all groups (Supplementary data, Figure S2A).

Fractional phosphate excretion significantly increased in the $\mathrm{CKD}$ control group compared with the sham group, whereas $\mathrm{MgCO}_{3}$ treatment in CKD mice or in combination 

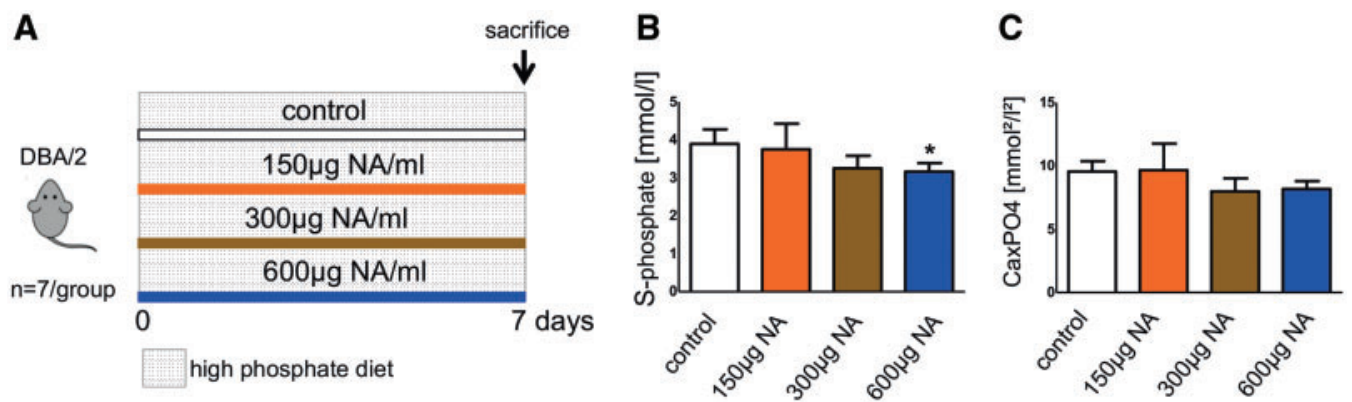

FIGURE 1: Dose finding study of NA in mice with HP. (A) 12-week-old DBA/2 mice ( $n=7$, females) received HP (1.65\% phosphate) together with no treatment (control = vehicle) or three different dosages of NA $(150,300$ or $600 \mu \mathrm{g} / \mathrm{mL})$ for 1 week via drinking water. (B) Serum phosphate levels at 1 week. (C) Calcium phosphate product at 1 week. ${ }^{\star} \mathrm{P}<0.05$ by one-way analysis of variance with post hoc Tukey test. All data represent mean \pm standard deviation.

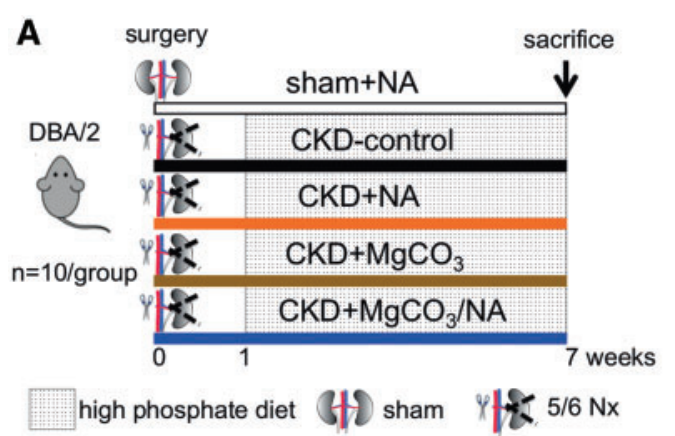

D

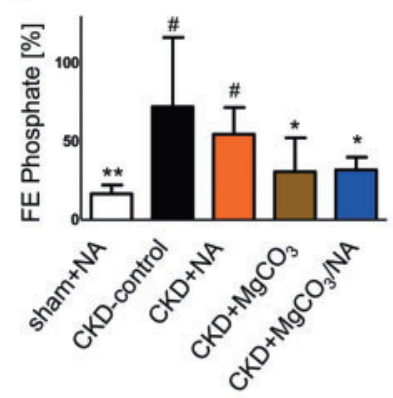

E

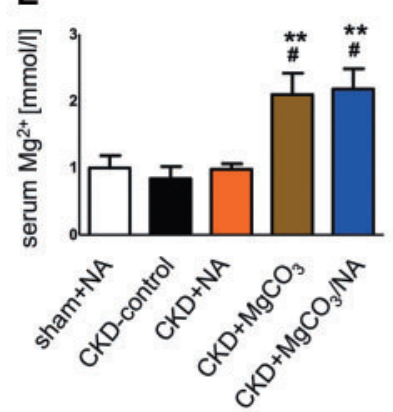

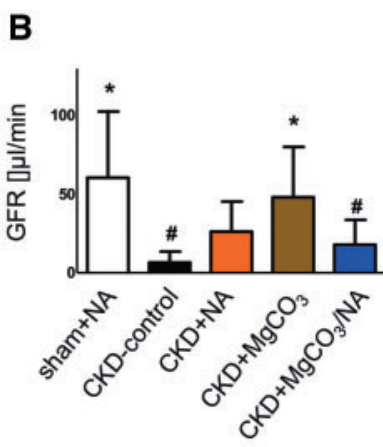

$\mathbf{F}$

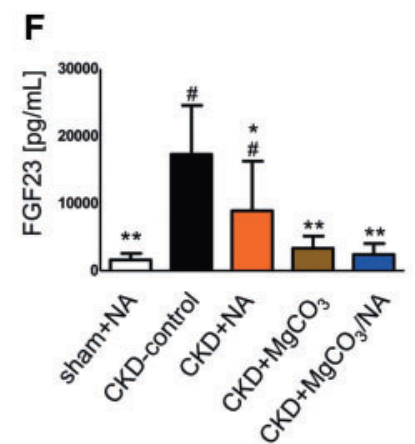

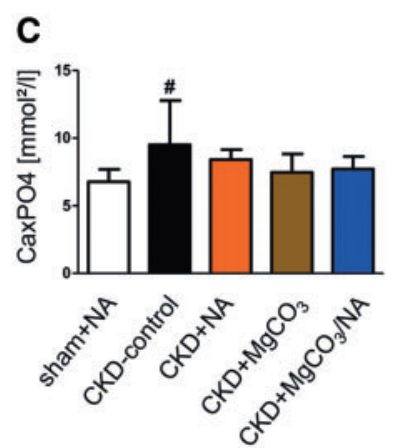

G

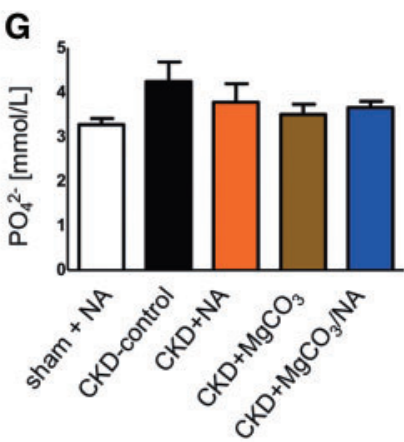

FIGURE 2: Treatment regime and effect on serum calcium and phosphate. (A) 12-week-old DBA/2 mice ( $n=10$ /group, all females) underwent sham surgery and received standard chow plus NA (sham + NA) via drinking water or were subjected to 5/6 nephrectomy followed by HP (1.65\% phosphate) with either no treatment (CKD control) or NA (CKD $+\mathrm{NA}), 3 \%$ magnesium carbonate $\left(\mathrm{CKD}+\mathrm{MgCO}_{3}\right)$ or a combination of both $\left(\mathrm{CKD}+\mathrm{MgCO}_{3} / \mathrm{NA}\right)$. Mice were sacrificed at 7 weeks after surgery. Two mice died after surgery in the NA group as well in the magnesium carbonate group. One mouse died in the combined therapy group. (B) GFR in the different groups at the time point of sacrifice. (C) Calciumphosphate product in the different groups at the time point of sacrifice. (D) Fractional phosphate excretion in the different groups at the time point of sacrifice. (E) Serum magnesium in the different groups at the time point of sacrifice (F) Serum FGF23 in the different groups at the time point of sacrifice. (G) Serum phosphate $\left(\mathrm{PO}_{4}^{2-}\right)$ in the different groups at sacrifice. ${ }^{*} \mathrm{P}<0.05 ;{ }^{* *} \mathrm{P}<0.001$ versus $\mathrm{CKD}$ control; ${ }^{\#} \mathrm{P}<0.05$ versus sham control; both by one-way analysis of variance with post hoc Tukey test. All data represent mean \pm standard deviation.

with $\mathrm{NA}\left(\mathrm{CKD}+\mathrm{MgCO}_{3} / \mathrm{NA}\right)$ resulted in reduced fractional phosphate excretion (Figure 2D). NA treatment in CKD alone did not show a significant effect on fractional phosphate excretion compared with the CKD control group. $\mathrm{MgCO}_{3}$ treatment doubled serum magnesium in the $\mathrm{CKD}+\mathrm{MgCO}_{3}$ and $\mathrm{CKD}+\mathrm{MgCO}_{3} / \mathrm{NA}$ groups (Figure $2 \mathrm{E}$ ). However, we did not observe significant effects on magnesium levels in the heart tissue (Supplementary data, Figure S2B). FGF23 was 10-fold elevated in the CKD control group compared with the sham group. All treatment groups showed significantly reduced FGF23 when compared with the CKD control group (Figure 2F).

\section{NA treatment reduces the magnesium carbonate- induced increased expression of intestinal $\mathrm{NaPi}$-IIb}

We asked whether any of the phosphate modulating and/or binding treatment regimes affect renal or intestinal expression of phosphate transporters. In the kidney, we observed a significant up-regulation of NaPi-IIb mRNA expression in the CKD control and CKD + NA groups compared with the sham group 

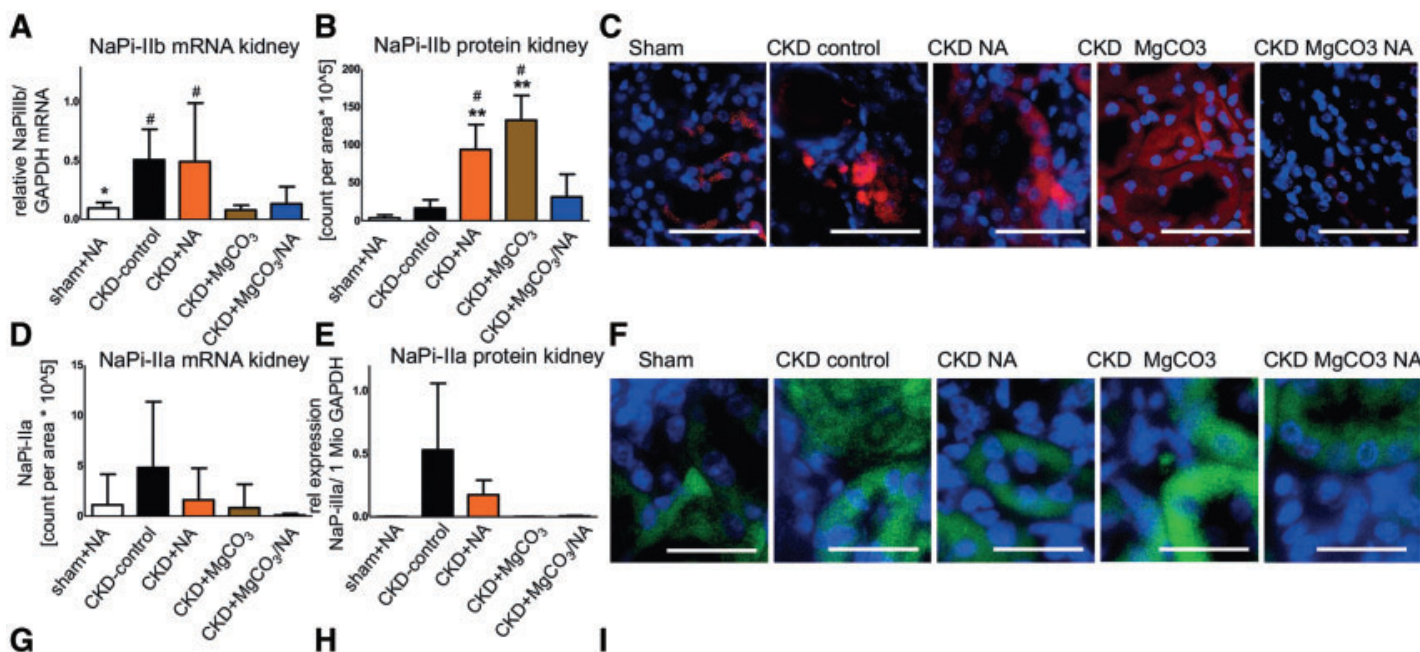

E NaPi-lla protein kidney ${ }_{\text {Sham }}$
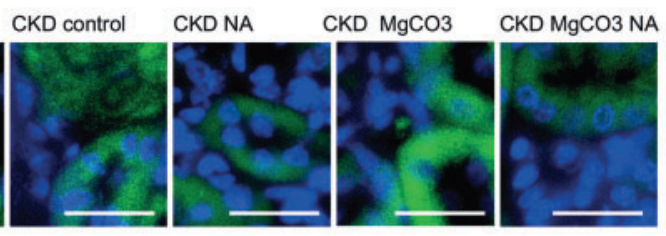

G

H $\quad$ o
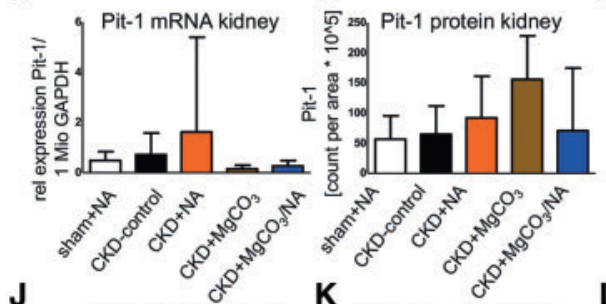

Sham
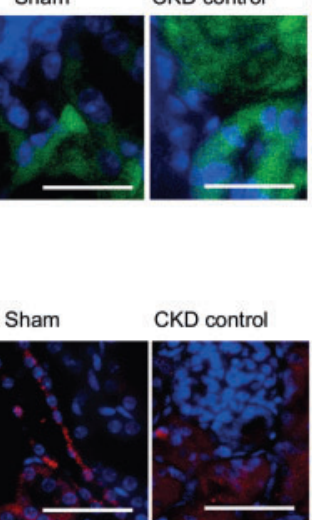

CKD control

CKD NA

CKD $\mathrm{MgCO} 3$

CKD MgCO3 NA

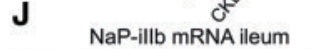

K NaPi-Ilb protein ileum

$\mathbf{L}_{\text {Sham }}$
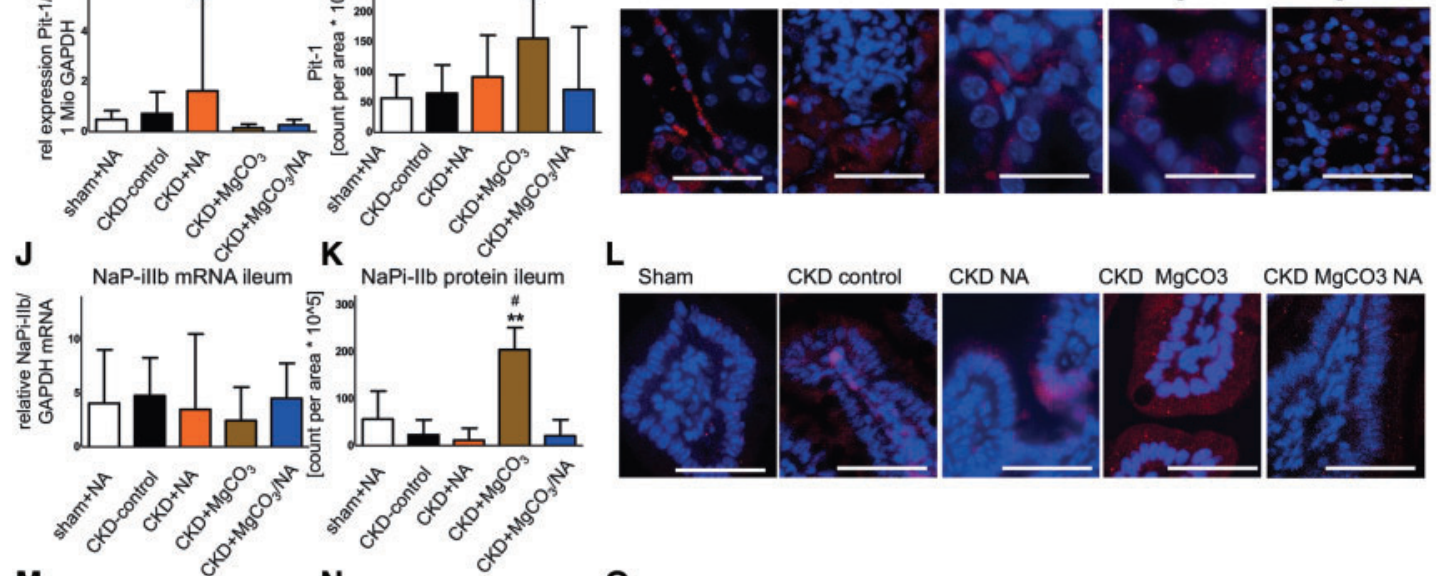

M NaPi-lla mRNA ileum

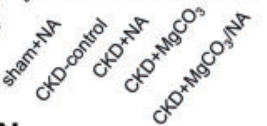

N NaPi-lla protein ileum

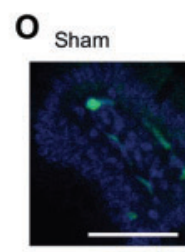

CKD control

CKD NA

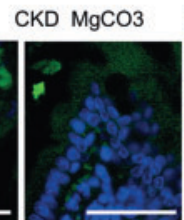

CKD MgCO3 NA
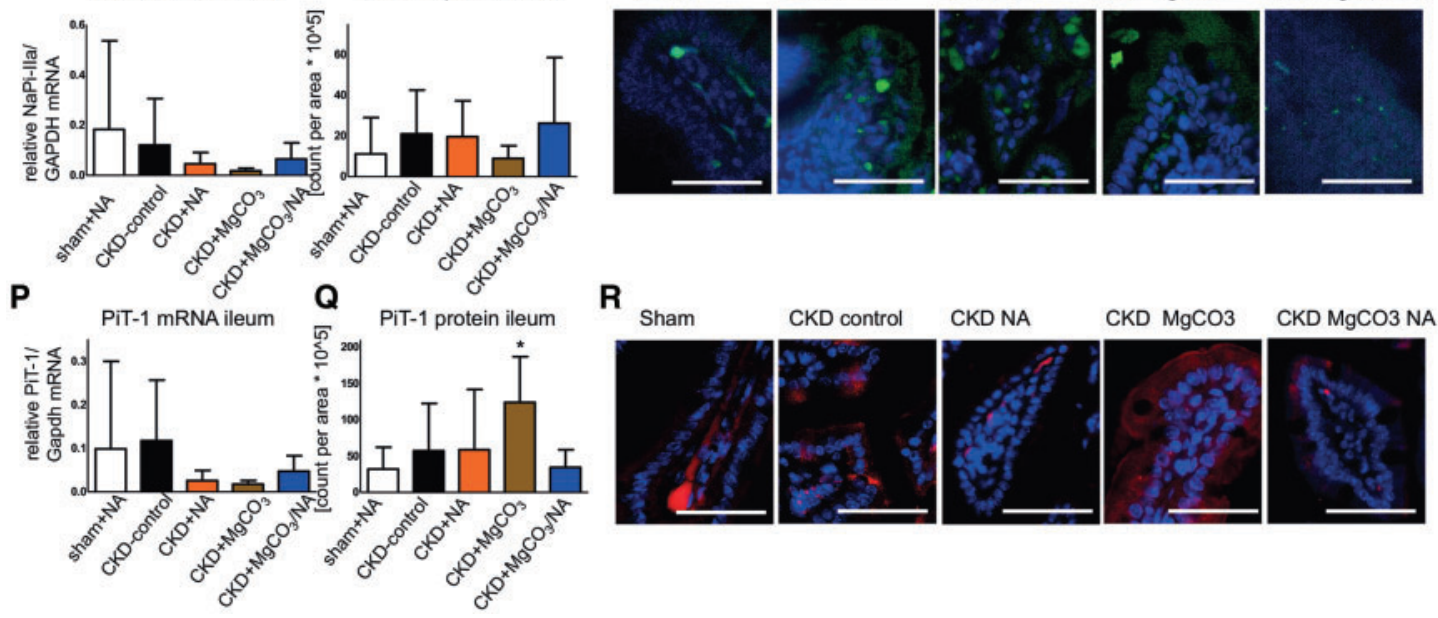

FIGURE 3: Effects of treatment regimes on intestinal and renal phosphate transporter expression. (A) mRNA expression of NaPi-IIb in the kidney. (B) Quantification of the immunofluorescence signal of NaPi-IIb in the kidney. (C) Representative pictures of immunofluorescence staining of NaPi-IIb in the kidney. (D) mRNA expression of NaPi-IIa in the kidney. (E) Quantification of the immunofluorescence signal of $\mathrm{NaPi}$-IIa in the kidney. (F) Representative pictures of immunofluorescence staining of NaPi-IIa in the kidney. (G) mRNA expression of Pit-1 in the kidney. (H) Quantification of the immunofluorescence signal of Pit-1 in the kidney. (I) Representative pictures of immunofluorescence staining of Pit-1 in the kidney. (J) mRNA expression of NaPi-IIb in the ileum. (K) Quantification of the immunofluorescence signal of NaPiIIb in the ileum. (L) Representative pictures of immunofluorescence staining of NaPi-IIb in the ileum. (M) mRNA expression of NaPi-IIa in the ileum. (N) Quantification of the immunofluorescence signal of NaPi-IIa in the ileum. (O) Representative pictures of immunofluorescence staining of NaPi-IIa in the ileum. (P) mRNA expression of Pit-1 in the ileum. (Q) Quantification of the immunofluorescence signal of Pit-1 in the ileum. (R) Representative pictures of immunofluorescence staining of Pit- 1 in the ileum. ${ }^{*} \mathrm{P}<0.05$; ${ }^{* *} \mathrm{P}<0.001$ versus $\mathrm{CKD}$ control;

${ }^{\#} \mathrm{P}<0.05$ versus sham control; both by one-way analysis of variance with post hoc Tukey test. All data represent mean \pm standard deviation. All scale bars $=100 \mu \mathrm{M}$. 
and both $\mathrm{MgCO}_{3}$-treated groups (Figure 3A). Immunostaining confirmed this finding at the protein level for the CKD + NA group but also showed increased expression in the $\mathrm{CKD}+\mathrm{MgCO}_{3}$ group (Figure $3 \mathrm{~B}$ and $\mathrm{C}$ ). Similar trends were found in the expression patterns of NaPi-IIa and Pit-1 in the kidneys within the treatment groups. No significant differences were found in NaPi-IIa and Pit-1 protein levels (Figure 3E-I).

Importantly, while the mRNA expression of NaPi-IIa, NaPiIIb and Pit-1 in the ileum was not significantly different between groups (Figure 3J, M and P), we observed significantly increased NaPi-IIb and Pit-1 protein expression in the ileum of $\mathrm{CKD}$ mice receiving $\mathrm{MgCO}_{3}$ alone, whereas the addition of NA completely inhibited this increased expression (Figure 3K, L, Q and $\mathrm{R}$ ). We did not detect any significant changes of NaPi-IIa expression (Figure 3M).

\section{NA increases calcification in CKD while the addition of magnesium carbonate can inhibit this process}

Next we analysed the calcium content in the aorta, heart and kidneys. As expected, the calcium content per milligram protein significantly increased in the CKD control group and von Kossa staining confirmed calcified areas in the heart, vascular wall and kidney (Figure 4). CKD mice treated solely with NA $(\mathrm{CKD}+\mathrm{NA})$ showed significantly more calcification in the heart and kidneys compared with the $\mathrm{CKD}$ control group. However, the addition of $\mathrm{MgCO}_{3}$ to the NA regime $\left(\mathrm{CKD}+\mathrm{NA} / \mathrm{MgCO}_{3}\right)$ significantly reduced calcification severity compared with the $\mathrm{CKD}$ control and $\mathrm{CKD}+\mathrm{NA}$ groups (Figure $4 \mathrm{~A}-\mathrm{F}$ ). Treatment with $\mathrm{MgCO}_{3}$ alone also showed reduced calcification severity compared with the CKD control and CKD + NA groups (Figure 4A-F).

Echocardiography revealed a significantly reduced stroke volume only in the $\mathrm{CKD}$ controls, whereas $\mathrm{EF}$ and pulse-wave velocity of the common carotid artery remained normal in all CKD groups (Supplementary data, Figure 3A-C).

\section{$\mathrm{N}$-methyl-2-pyridone-5-carboxamide increases dose- dependent alkaline phosphatase activity in Gli1 ${ }^{+}$ progenitor cells}

Finally, we investigated whether the effect of NA and/or $\mathrm{MgCO}_{3}$ on calcification severity can be explained by a direct effect on the cells that drive the calcification process or whether it is more likely due to an effect on intestinal phosphate absorption with a subsequently reduced calcium phosphate product. As VSMCs and their recently discovered adventitial $\mathrm{Gli1}^{+}$progenitors are the cellular drivers of vascular calcification [3], we tested the effect of the above-mentioned treatment combinations on calcification severity using in vitro calcification assays of both cell types. In addition to NA treatment, we also used its active metabolite 2PY. Osteogenic differentiation medium resulted in increased alkaline phosphatase activity and increased calcium levels as readouts of calcification in VSCMs and $\mathrm{Gli1}^{+}$cells (Figure 5A-F). None of the treatment conditions significantly changed these readouts in VSMCs. Interestingly, in $\mathrm{Gli1}^{+}$cells exposed to osteogenic differentiation medium, alkaline phosphatase activity was significantly reduced by the addition of $\mathrm{Na}+\mathrm{MgCO}_{3}$. However, $10 \mu \mathrm{M} 2 \mathrm{PY}$ significantly increased alkaline phosphatase activity as a potential early pro-calcificatory mechanism. We also evaluated the in vitro effect of another active metabolite of NA, namely $4 \mathrm{PY}$. Interestingly, 4PY treatment showed reduced osteogenic differentiation of $\mathrm{Glil}^{+}$cells with a significant reduction in alkaline phosphatase activity (Figure 5A-F). We also observed a tendency towards reduced calcium deposition in both VSMCs and Gli1 ${ }^{+}$ cells following 4PY treatment (Figure 5A-F).

\section{DISCUSSION}

In this study we analysed the influence of oral NA and/or $\mathrm{MgCO}_{3}$ on vascular and soft tissue calcification and intestinal phosphate transporter expression in $\mathrm{DBA} / 2$ mice with $\mathrm{CKD}$. The strength of our study is the multiple treatment approach combining two different therapies with potential additive effects and confirming this in vitro. DBA/ 2 mice are particularly susceptible to tissue calcification due to mutation of the $h r c$ (histidinerich calcium-binding protein) gene on chromosome 7 [29, 30]. Our most important finding is that although all treatment regimes showed similar effects on serum phosphate and the calcium-phosphate product, NA treatment alone resulted in increased soft tissue and vascular calcification, whereas the addition of $\mathrm{MgCO}_{3}$ significantly reduced it in CKD mice. $\mathrm{MgCO}_{3}$ treatment also resulted in increased intestinal expression of the phosphate transporters NaPi-IIb and Pit-1. Whether these changes include functional changes in phosphate transporters should be analysed in a future study, for example, by measuring the phosphate passage through ex vivo intestinal membrane preparations. However, $\mathrm{MgCO}_{3}$ treatment alone resulted in reduced calcification severity with and without NA treatment. The addition of NA normalized the increased levels of intestinal phosphate transporter expression. Thus our data suggest that a therapy of $\mathrm{MgCO}_{3}$ might be beneficial, whereas the question of whether a combined therapy with NA adds additional benefit remains unclear. According to the double increase of serum magnesium, we cannot exclude any systemic effects of those treatments. Given the multiple beneficial effects reported for supplemental magnesium and the recent report that magnesium might directly inhibit hydroxyapatite crystal formation [31], the increased serum magnesium might explain the decreased calcification at least partly outside the effect of magnesium carbonate as a phosphate binder. Because calcium content differed most in the myocardium, we measured the magnesium content as well. Cardiac tissue magnesium content remained unchanged. However, the increased serum magnesium might certainly have an effect on calcification, which we cannot exclude. Given the multiple beneficial effects reported for magnesium as a supplement and the recent report that magnesium might directly inhibit hydroxyapatite crystal formation [31], the increased serum magnesium might explain the decreased calcification at least partly outside of the effect of $\mathrm{MgCO}_{3}$ as a phosphate binder.

Major issues of oral phosphate binders are the high pill burden and adverse effects, mainly gastrointestinal intolerance, and thus patients often take phosphate binders irregularly, resulting in decreased dosage. Intestinal adaptation to phosphate binding therapy with increased expression of phosphate transporters, as demonstrated in our experiments with $\mathrm{MgCO}_{3}$ treatment, might result in increased intestinal phosphate absorption and 


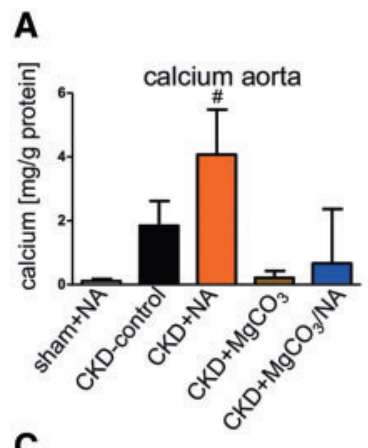

B

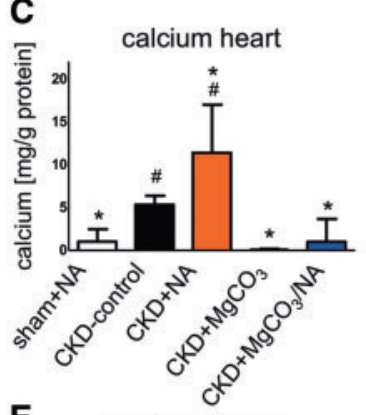

D
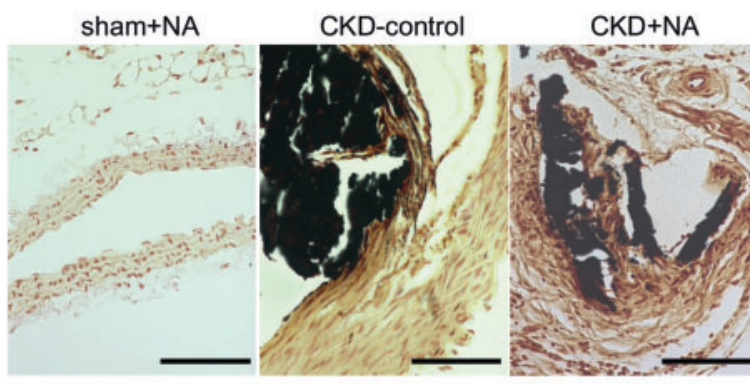

$\mathrm{CKD}+\mathrm{MgCO}_{3}$
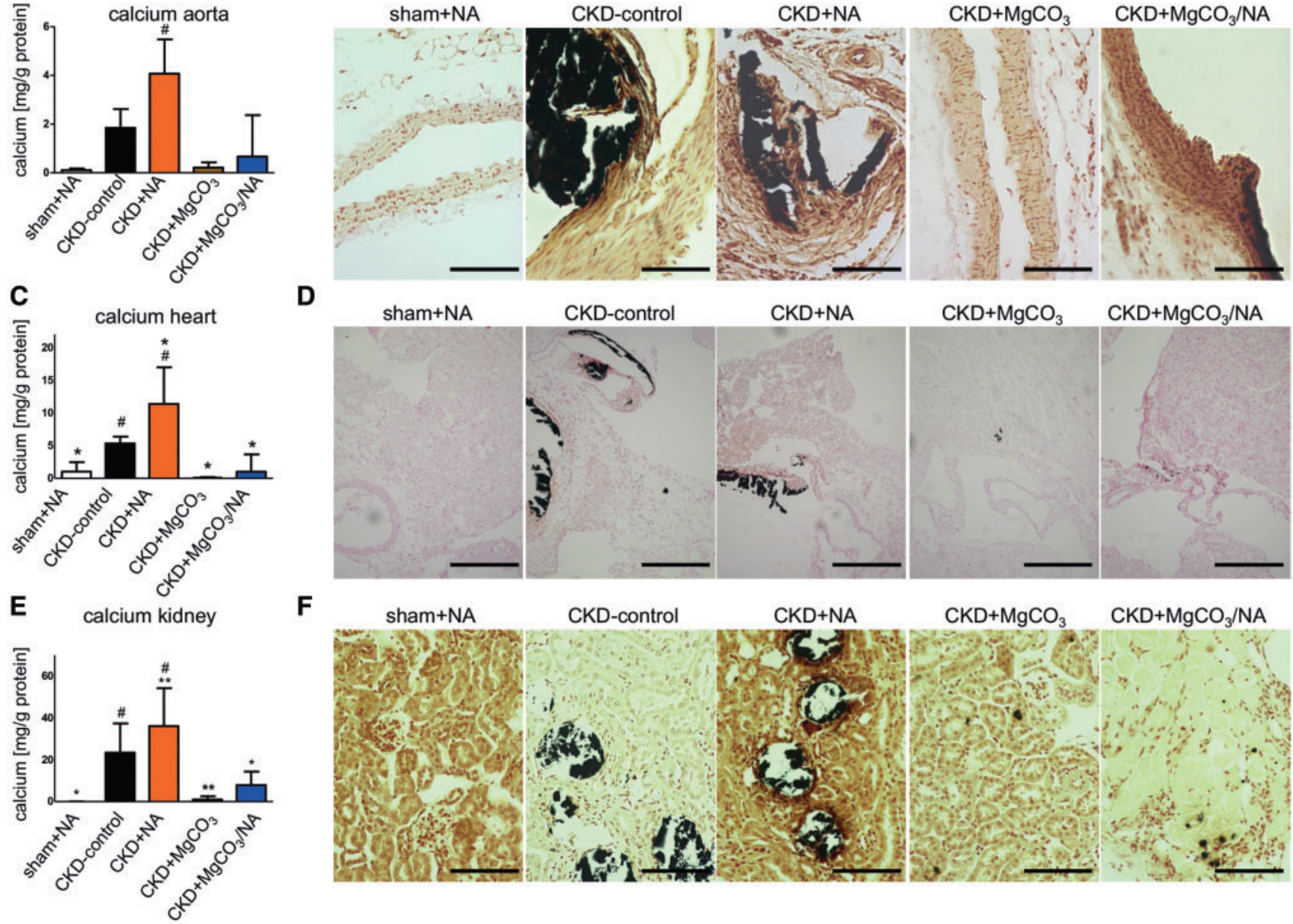

$\mathbf{F}$

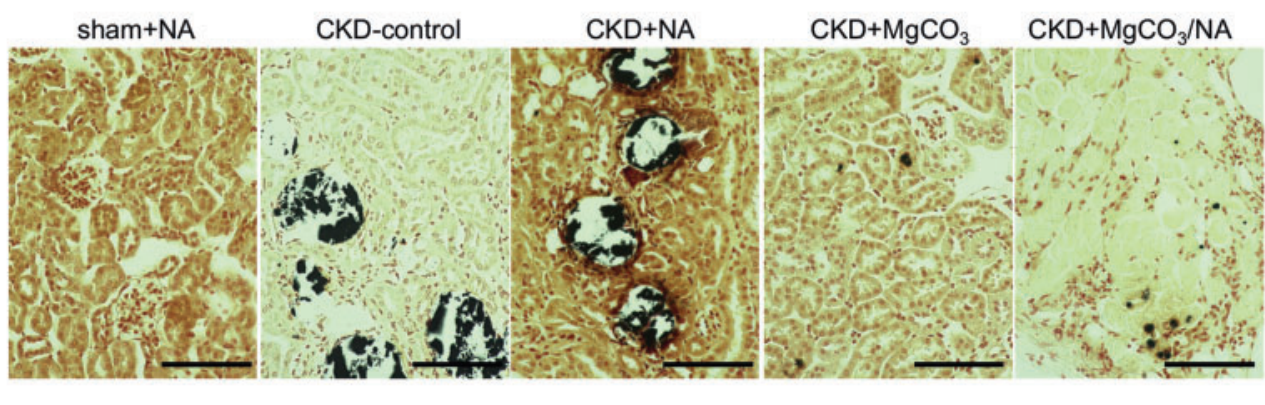

FIGURE 4: Effects of NA and $\mathrm{MgCO}_{3}$ treatment on vascular and soft tissue calcification. (A) Calcium quantification in the aorta. (B) Representative images of von Kossa-stained section of the aorta. (C) Calcium quantification in the heart. (D) Representative von Kossastained heart images. (E) Quantification of calcium in the kidney. (F) Representative images of von Kossa-stained kidney. ${ }^{\star} \mathrm{P}<0.05$; ${ }^{*} \mathrm{P}<0.001$ versus CKD control; ${ }^{*} \mathrm{P}<0.05$ versus sham control; both by one-way analysis of variance with post hoc Tukey test. All data represents mean \pm standard deviation. Scale bar $=100 \mu \mathrm{M}$.

thus counteract the treatment goal. In agreement with this conclusion, sevelamer treatment in wild-type mice resulted in higher serum phosphate levels when compared with NaPi-IIb knockout mice [32].

The addition of NA might counteract the above intestinal response and thus helps to decrease pill burden and phosphate load. Given a phosphate-lowering monotherapy, NA does not appear to be acceptable. Thus Malhotra et al. [24] reported only minor efficacy of extended niacin compared with placebo in a subgroup analysis of the Atherothrombosis Intervention in Metabolic Syndrome with low HDL/HIGH Triglycerides trial in patients with dyslipidaemia and a GFR $<60 \mathrm{~mL} / \mathrm{min} / 1.73 \mathrm{~m}^{2}$. The trial of Lenglet et al. [25] aimed for non-inferiority and safety of NA versus sevelamer and reported a comparable decrease in serum phosphate in 100 dialysis patients. However, the criterion for non-inferiority was not met due to a smaller number of patients being included than planned. Beyond these clinical observations, our data show that NA monotherapy in CKD can also increase tissue calcification. The reason for this remains unclear; however, our finding is in line with the observation of increased cardiac calcium levels in a mouse model of tumoural calcinosis treated with NA [33]. We failed to obtain a significant difference in aortic calcium content/vascular calcification in CKD mice compared with the control group. Therefore we also investigated VSMC and $\mathrm{Glil}^{+}$pericyte calcification in vitro. Here we evaluated whether the effect of NA on vascular calcification severity can be explained by direct effects on the cells that drive this process. $2 \mathrm{PY}$, the active metabolite of NA, is increased in CKD patients and has been discussed as a uraemic toxin [34]. Hence we also asked whether 2PY might be involved in the increased calcification severity we have observed in NA-treated mice. $2 \mathrm{PY}$ treatment promoted alkaline phosphatase activity in calcifying Gli1 ${ }^{+}$cells. As the calcium content was not increased by $2 \mathrm{PY}$, we probably identified an early procalcificatory effect of $2 \mathrm{PY}$, which should be analysed further in an animal study. We also evaluated the effect of $4 \mathrm{PY}$, another active metabolite of NA. Interestingly, we observed a tendency towards less calcium deposition and reduced alkaline phosphatase activity in $\mathrm{Gli1}^{+}$ cells.

We have to point out that major physiological differences between mice and humans exist with regard to intestinal phosphate transport. For example, in humans, NaPi-IIb is mainly 
A
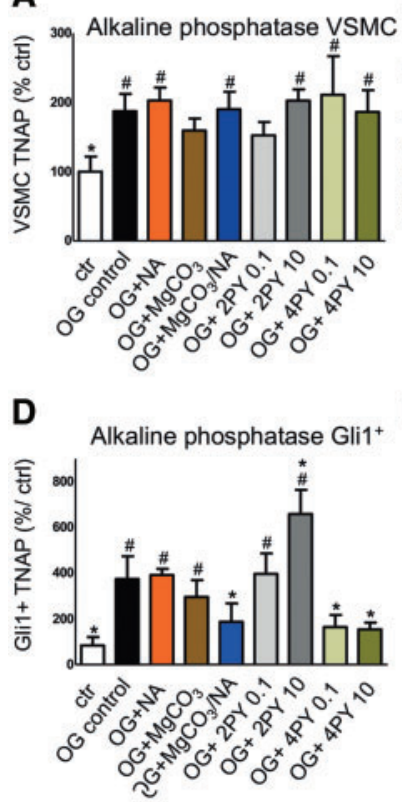

B

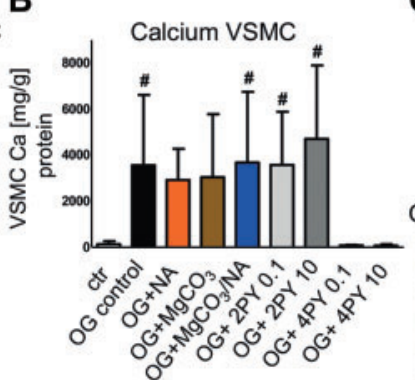

E

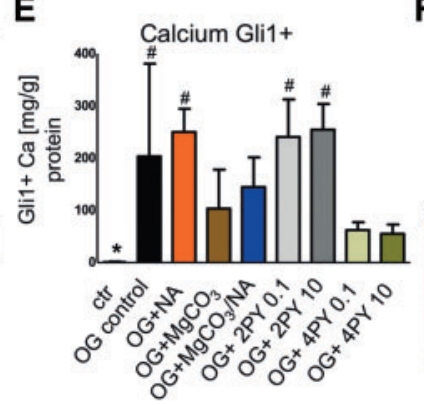

C

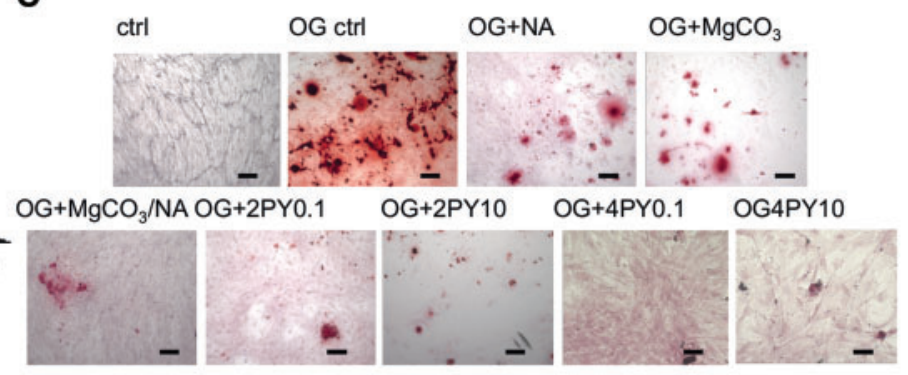

$\mathbf{F}$

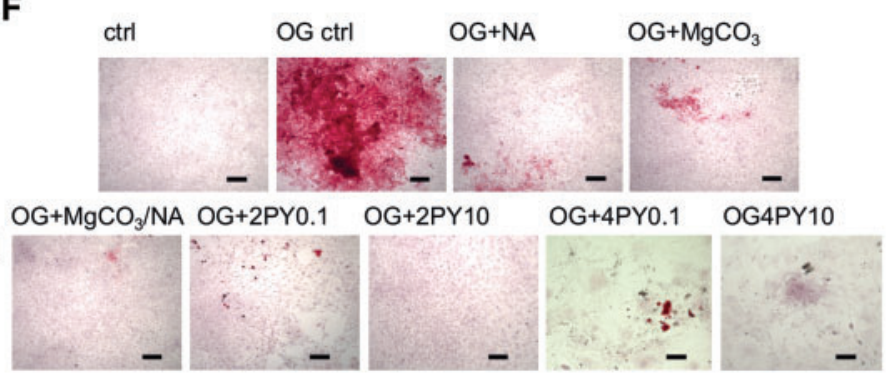

FIGURE 5: In vitro calcification of human VSMCs and murine Gli1 ${ }^{+}$cells. (A) Tissue non-specific alkaline phosphatase activity in VSMC. (B) Calcium deposition in VSMC. (C) Alizarin red staining in VSMC in all groups. (D) Tissue non-specific alkaline phosphatase activity in Gli1 $^{+}$cells. (E) Calcium deposition in Gli1 ${ }^{+}$cells. (F) Alizarin red staining in Gli1 ${ }^{+}$cells in all groups. OG, osteogenic medium; TNAP, tissue non-specific alkaline phosphatase. ${ }^{*} \mathrm{P}<0.05$ versus control; ${ }^{*} \mathrm{P}<0.05$ versus $\mathrm{OG}$ control; both by one-way analysis of variance with post hoc Tukey test. All data represent mean \pm standard deviation. All scale bars $=200 \mu \mathrm{M}$.

located in the duodenum and jejunum, whereas in mice it is mainly located in the ileum [35]. Furthermore, in mice, we usually cannot obtain CKD stages beyond stage 3 . Next, our dosefinding study was performed in healthy mice and not in CKD mice. The serum phosphate level did not significantly change in the CKD mice treated with NA and thus it might be that testing NA in CKD mice would have resulted in a different dosage regime. At $600 \mu \mathrm{g} / \mathrm{mL} \mathrm{NA}$, we found a significant reduction of serum phosphate in healthy mice. Of note, the NA dosage used in this study is approximately 6-fold higher compared with the dosage used in clinical trials. We can therefore not exclude that this high dose might have resulted in toxic effects that partly explain the increased calcification. We did not measure serum concentration of NA, $2 \mathrm{PY}$ or $4 \mathrm{PY}$, which is a limitation of the study. However, pharmacokinetic data for NA in mice are well documented [36], providing valuable data to set the dosage for the in vitro experiments. Another limitation of the study is that we only focus on one calcification model. DBA/2 mice might be particularly sensitive to magnesium [37] and therefore other models will have to be studied to see if the beneficial effects of $\mathrm{MgCO}_{3}$ can be reproduced. However, in line with our results, magnesium has already been described to counteract in vitro smooth muscle cell calcification [28].

Given that our experimental study and two recent clinical trials did not support the use of niacin and NA alone to control serum phosphate in CKD patients [23-25], the addition of $\mathrm{MgCO}_{3}$ might be an option.

\section{SUPPLEMENTARY DATA}

Supplementary data are available at ndt online.

\section{ACKNOWLEDGEMENTS}

We thank Katrin Härthe, Nina Graff and Peggy Jirak for excellent technical assistance.

\section{FUNDING}

The study was supported by a grant from Medice Pharma (to N.K.) and by a grant from the German Research Foundation to J.F. SFB TRR291 TP C01 and by Grants of the German Research Foundation (KR-4073/3-1, SCHN1188/5-1, SFB/ TRR57, SFB TRR219 TP C05), the European Research Council (ERC-StG 677448), a START Grant from the RWTH Aachen University (101/15), the State of Northrhinewestfalia (Return to NRW) and a grant from the Interdisciplinary Centre for Clinical Research within the faculty of Medicine at the RWTH Aachen University (O3-11 to R.K.).

\section{CONFLICT OF INTEREST STATEMENT}

The authors received funding from Medice Pharma B.H. is employed by Medice Pharma.

(See related article by Drüeke and Massy. Vascular calcification-any place left for nicotinamide? Nephrol Dial Transplant 2020; 35: 18-22)

\section{REFERENCES}

1. Hill NR, Fatoba ST, Oke JL et al. Global prevalence of chronic kidney disease - a systematic review and meta-analysis. PLoS One 2016; 11: e0158765 
2. Kramann R, Floege J, Ketteler M et al. Medical options to fight mortality in end-stage renal disease: a review of the literature. Nephrol Dial Transplant 2012; 27: 4298-4307

3. Kramann R, Goettsch C, Wongboonsin J et al. Adventitial MSC-like cells are progenitors of vascular smooth muscle cells and drive vascular calcification in chronic kidney disease. Cell Stem Cell 2016; 19: 628-642

4. Kramann R, Erpenbeck J, Schneider RK et al. Speckle tracking echocardiography detects uremic cardiomyopathy early and predicts cardiovascular mortality in ESRD. J Am Soc Nephrol 2014; 25: 2351-2365

5. Goettsch C, Hutcheson JD, Aikawa M et al. Sortilin mediates vascular calcification via its recruitment into extracellular vesicles. J Clin Invest 2016; 126 : 1323-1336

6. Adeney KL, Siscovick DS, Ix JH et al. Association of serum phosphate with vascular and valvular calcification in moderate CKD. J Am Soc Nephrol 2009; 20: 381-387

7. Shanahan CM, Crouthamel MH, Kapustin A et al. Arterial calcification in chronic kidney disease: key roles for calcium and phosphate. Circ Res 2011; 109: 697-711

8. Shang D, Xie Q, Ge X et al. Hyperphosphatemia as an independent risk factor for coronary artery calcification progression in peritoneal dialysis patients. BMC Nephrol 2015; 16: 107

9. Finch JL, Lee DH, Liapis $\mathrm{H}$ et al. Phosphate restriction significantly reduces mortality in uremic rats with established vascular calcification. Kidney Int 2013; 84: 1145-1153

10. Block GA, Spiegel DM, Ehrlich J et al. Effects of sevelamer and calcium on coronary artery calcification in patients new to hemodialysis. Kidney Int 2005; 68: 1815-1824

11. de Oliveira RB, Louvet L, Riser BL et al. Peritoneal delivery of sodium pyrophosphate blocks the progression of pre-existing vascular calcification in uremic apolipoprotein-E knockout mice. Calcif Tissue Int 2015; 97: 179-192

12. Jamal SA, Vandermeer B, Raggi $P$ et al. Effect of calcium-based versus noncalcium-based phosphate binders on mortality in patients with chronic kidney disease: an updated systematic review and meta-analysis. Lancet 2013; 382: 1268-1277

13. Lopes AA, Tong L, Thumma J et al. Phosphate binder use and mortality among hemodialysis patients in the Dialysis Outcomes and Practice Patterns Study (DOPPS): evaluation of possible confounding by nutritional status. Am J Kidney Dis 2012; 60: 90-101

14. Neven E, De Schutter TM, Dams G et al. A magnesium based phosphate binder reduces vascular calcification without affecting bone in chronic renal failure rats. PLoS One 2014; 9: e107067

15. De Schutter TM, Behets GJ, Geryl H et al. Effect of a magnesium-based phosphate binder on medial calcification in a rat model of uremia. Kidney Int 2013; 83: 1109-1117

16. Khan AM, Lubitz SA, Sullivan LM et al. Low serum magnesium and the development of atrial fibrillation in the community: the Framingham Heart Study. Circulation 2013; 127: 33-38

17. Oka T, Hamano T, Sakaguchi Y et al. Proteinuria-associated renal magnesium wasting leads to hypomagnesemia: a common electrolyte abnormality in chronic kidney disease. Nephrol Dial Transplant 2019; 34: 1154-1162

18. Marks J, Debnam ES, Unwin RJ. The role of the gastrointestinal tract in phosphate homeostasis in health and chronic kidney disease. Curr Opin Nephrol Hypertens 2013; 22: 481-487
19. Kaneko I, Tatsumi S, Segawa $\mathrm{H}$ et al. Control of phosphate balance by the kidney and intestine. Clin Exp Nephrol 2017; 21: 21-26

20. Sabbagh Y, Giral H, Caldas Y et al. Intestinal phosphate transport. $A d v$ Chronic Kidney Dis 2011; 18: 85-90

21. Hattenhauer $\mathrm{O}$, Traebert $\mathrm{M}$, Murer $\mathrm{H}$ et al. Regulation of small intestinal Na-P(i) type IIb cotransporter by dietary phosphate intake. Am J Physiol 1999; 277: G756-G762

22. Cheng SC, Young DO, Huang Y et al. A randomized, double-blind, placebo-controlled trial of niacinamide for reduction of phosphorus in hemodialysis patients. Clin J Am Soc Nephrol 2008; 3: 1131-1138

23. Drueke TB, Massy ZA. Lowering expectations with niacin treatment for CKD-MBD. Clin J Am Soc Nephrol 2018; 13: 6-8

24. Malhotra R, Katz R, Hoofnagle A et al. The effect of extended release niacin on markers of mineral metabolism in CKD. Clin J Am Soc Nephrol 2018; 13: 36-44

25. Lenglet A, Liabeuf S, Esper NE et al. Efficacy and safety of nicotinamide in haemodialysis patients: the NICOREN study. Nephrol Dial Transplant 2017; 32: 1597

26. Kaesler N, Verhulst A, De Mare A et al. Sclerostin deficiency modifies the development of CKD-MBD in mice. Bone 2018; 107: 115-123

27. Kramann R, Schneider RK, DiRocco DP et al. Perivascular Gli1 ${ }^{+}$progenitors are key contributors to injury-induced organ fibrosis. Cell Stem Cell 2015; 16: 51-66

28. Kaesler N, Immendorf S, Ouyang C et al. Gas6 protein: its role in cardiovascular calcification. BMC Nephrol 2016; 17: 52

29. Davis RC, Schadt EE, Smith DJ et al. A genome-wide set of congenic mouse strains derived from DBA/2J on a C57BL/6J background. Genomics 2005; 86: $259-270$

30. van den Broek FA, Bakker R, den Bieman M et al. Genetic analysis of dystrophic cardiac calcification in DBA/2 mice. Biochem Biophys Res Commun 1998; 253: 204-208

31. ter Braake AD, Tinnemans PT, Shanahan CM et al. Magnesium prevents vascular calcification in vitro by inhibition of hydroxyapatite crystal formation. Sci Rep 2018; 8: 2069

32. Schiavi SC, Tang W, Bracken $\mathrm{C}$ et al. Npt2b deletion attenuates hyperphosphatemia associated with CKD. J Am Soc Nephrol 2012; 23: 1691-1700

33. Reilly AM, Gray AK, Moe SM et al. Nicotinamide treatment in a murine model of familial tumoral calcinosis reduces serum Fgf 23 and raises heart calcium. Bone 2014; 67: 139-144

34. Rutkowski B, Slominska E, Szolkiewicz M et al. N-methyl-2-pyridone-5carboxamide: a novel uremic toxin? Kidney Int 2003; 63: S19-S21

35. Wagner CA, Hernando N, Forster IC et al. The SLC34 family of sodiumdependent phosphate transporters. Pflugers Arch 2014; 466: 139-153

36. Stratford MR, Dennis MF. Pharmacokinetics and biochemistry studies on nicotinamide in the mouse. Cancer Chemother Pharmacol 1994; 34 399-404

37. van den Broek FA, Beynen AC. The influence of dietary phosphorus and magnesium concentrations on the calcium content of heart and kidneys of DBA/2 and NMRI mice. Lab Anim 1998; 32: 483-491

Received: 21.8.2018; Editorial decision: 13.12.2018 